\title{
Activity of 5-HT1A receptor is involved in neuronal apoptosis of the amygdala in a rat model of post-traumatic stress disorder
}

\author{
HONG LIU $^{1}$, HAI-TAO WANG ${ }^{2}$, FANG HAN ${ }^{1}$ and YU-XIU SHI ${ }^{1}$ \\ ${ }^{1}$ Department of Histology and Embryology, Basic Medical Sciences College, China Medical University, Shenyang 110001; \\ ${ }^{2}$ Department of Histology and Embryology, North China Coal Medical University, Tangshan 063000, P.R. China
}

Received September 28, 2010; Accepted December 24, 2010

DOI: $10.3892 / \mathrm{mmr} .2011 .415$

\begin{abstract}
Evidence suggests that the volume of the amygdala is significantly reduced in patients with post-traumatic stress disorder (PTSD), and that this may be related to neuronal apoptosis. However, the precise molecular mechanism of this decrease in amygdala volume during PTSD remains unclear. In this study, we investigated the relationship between the activity of the 5-HT1A receptor and amygdala neuronal apoptosis. Rats were exposed to a single-prolonged stress (SPS) procedure to create a PTSD rat model, with or without prior treatment with WAY100635, a 5-HT1A receptor antagonist. The expression of Bax, a pro-apoptotic protein, and Bcl-2, an anti-apoptotic protein, was examined by Western Blotting. TUNEL staining and flow cytometry (FCM) were employed for the detection of apoptotic cells in the amygdala. Our results indicate that SPS induces amygdala neuronal apoptosis, which was partially inhibited by WAY100635, and suggest that this apoptosis may be related to the activity of the 5-HT1A receptor.
\end{abstract}

\section{Introduction}

Post-traumatic stress disorder (PTSD) is an anxiety disorder that develops after endurance of a life-threatening traumatic experience and consists of re-experiencing trauma with distressing recollections, dreams, flashbacks, psychological/ physical distress, persistent avoidance of stimuli that might invite traumatic memories or expericences, and increased emotional arousal (1). The exact mechanism of PTSD remain elusive. Single-prolonged stress (SPS) appears to induce enhanced inhibition of the hypothalamic-pituitary-adrenal (HPA) axis, which is a putative neuroendocrinological hall-

Correspondence to: Professor Yuxiu Shi, Department of Histology and Embryology, Basic Medical Sciences College, China Medical University, 92 North 2nd Road, Shenyang, Liaoning 110001, P.R. China

E-mail: shiyuxiu01@163.com

Key words: serotonin type $1 \mathrm{~A}$ receptor, single-prolonged stress, post-traumatic stress disorder, amygdala, apoptosis mark of PTSD. SPS paradigms have been extensively applied in the investigation of PTSD.

PTSD is thought to involve the dysregulation of amygdala activity in response to fear. Certain regions of the brain, in particular the amygdala and hippocampus, are involved in the pathophysiology of PTSD. The amygdala is the main output center of response to fearful stimuli (2), and has been documented to be responsible for the enhancement of explicit memories associated with emotional arousal $(3,4)$. The amygdala is closely related to the hippocampus, and the clinical course of PTSD is driven by pathophysiological changes in these brain regions. Abundant evidence suggest that the volume of the amygdala in patients suffering from PTSD is significantly reduced $(5,6)$. Ding et al detected the expression of apoptosis-related genes and observed morphological changes in the amygdala neurons of PTSD rats (7). Apoptosis is regulated by various classes of proteins, including the proapoptotic protein Bax and the anti-apoptotic protein Bcl-2. The $\mathrm{Bax} / \mathrm{Bcl}-2$ ratio appears to be a critical threshold parameter for apoptosis $(8,9)$. Serotonin (5-hydroxytryptamine, 5-HT), a type of neurotransmitter, plays an important role in controlling complex neuronal communication, such as the negative feedback of the HPA axis via the serotonergic receptor $(10,11)$. It has been proposed that the serotonergic type 1A (5-HT1A) receptor plays a crucial role in mood and anxiety modulation $(12,13)$. However, the role of the serotonin receptor in PTSD appears contradictory $(14,15)$. One of our previous studies revealed that the 5-HT1A receptor is involved in the alteration of glucocorticoid receptor in the hippocampus and corticotropin releasing factor in the hypothalamus in SPS rats (16). Whether the 5-HT1A receptor is activated during SPS in the amygdala and whether its role in apoptosis is induced by SPS remains to be determined. In the present study, rats were exposed to SPS with or without prior treatment with the 5-HT1A receptor antagonist WAY100635, and the expression of $\mathrm{Bax} / \mathrm{Bcl}-2$ and apoptotis in the amygdala of the SPS rats was examined in order to elucidate the role of the 5-HT1A receptor in apoptotis.

\section{Materials and methods}

Animals. Healthy male Wistar rats $(\mathrm{n}=45)$ weighing $180-220 \mathrm{~g}$ were obtained from the Experimental Animal Center of China Medical University. Prior to the experiment, they were reared 
in the experimental animal facility for a week to acclimate them to the new environment: temperature $18-20^{\circ} \mathrm{C}$, humidity 50-60\%, and lights on from 07:00 to 19:00. Standard food pellets and tap water were available ad libitum. All procedures followed national guidelines for animal care.

Animal PTSD model and experimental groups. The rats were randomly divived into three groups: the control group, the model group and the blockade group. The model and blockade groups were injected with either solvent or WAY100635 30 min prior to undegoing the SPS procedure. The control rats were administred an equal volume of solvent. The PTSD model was created as previously described (17). Briefly, rats were restrained for $2 \mathrm{~h}$ and then immediately forced to swim for $20 \mathrm{~min}$ in water at $24^{\circ} \mathrm{C}$. After a 15 -min rest, they were anaesthetized by ether and then placed in their home cages without disturbance.

Drug infusion procedure. WAY100635 (Sigma, USA) was dissolved in DMSO $(50 \mathrm{mg} / \mathrm{ml})$ and stored at $-20^{\circ} \mathrm{C}$. The solution was diluted in physiological normal saline before use to a final concentration of $0.5 \mathrm{mg} / \mathrm{ml}$. A dose of $3.0 \mathrm{mg} / \mathrm{kg}$ WAY100635 was administered by subcutaneous infusion (18).

Western blotting for Bax and Bcl-2. Seven days after exposure to SPS, five rats in each group were decapitated and Western blotting was used to determine the levels of $\mathrm{Bax} / \mathrm{Bcl}-2$ in the amydala. The brains were removed and the basolateral amygdala was dissected according to the atlas of Paxinos and Watson (19). Tissue samples were homogenized in ice-cold lysis buffer containing $50 \mathrm{mM}$ Tris- $\mathrm{HCl}(\mathrm{pH} 7.4), 1 \% \mathrm{NP}-40$, $0.25 \%$ nadeoxycholate, $150 \mathrm{mM} \mathrm{NaCl}, 1 \mathrm{mM}$ PMSF, $1 \mathrm{mM}$ EDTA, $1 \mathrm{mg} / \mathrm{ml}$ pepstatin, $1 \mathrm{mM} \mathrm{Na} \mathrm{VO}_{4}$ and $1 \mathrm{mM} \mathrm{NaF}$. Crude homogenates were incubated on ice for $30 \mathrm{~min}$ and centrifuged at $15,000 \mathrm{~g}$ for $30 \mathrm{~min}$ at $4^{\circ} \mathrm{C}$. The supernatant was collected for protein assay and stored at $-70^{\circ} \mathrm{C}$. Samples (30 $\mu \mathrm{g}$ protein per lane) were separated in 10\% SDS-PAGE and transferred onto PVDF membranes. The membranes were blocked in blocking solution $(5 \%$ skim milk, $10 \mathrm{mM}$ Tris- $\mathrm{HCl}, 100 \mathrm{mM} \mathrm{NaCl}, 0.01 \%$ Tween-20) for $2 \mathrm{~h}$ at room temperature, immersed in mouse monoclonal anti-Bax or antiBcl-2 antibodies (1:1000; Cell Signaling, Beverly, MA, USA) and maintained overnight at $4^{\circ} \mathrm{C}$. Membranes were washed three times for $10 \mathrm{~min}$ each in TBST $(10 \mathrm{mM}$ Tris- $\mathrm{HCl}$, $100 \mathrm{mM} \mathrm{NaCl}, 0.01 \%$ Tween-20) and incubated for $2 \mathrm{~h}$ with horseradish peroxidase-conjugated secondary antibody and goat polyclonal anti-mouse IgG (1:2500; Boster Biological Technology Ltd., Wuhan, China). After the membranes were washed, the specific bands were detected by an ECL system. $\beta$-actin was used for the controls. The bands were analyzed by the Gel Image Analysis System (Tanon 2500R, Shanghai, China). Each Bax or Bcl-2 band was normalized to $\beta$-actin values and expressed as the intensity ratio.

Double-labeled flow cytometry for cell apoptosis rate. Seven days after exposure to SPS, five rats from each group were decapitated and double-labeled flow cytometry (FCM) was used to determine the rate of cell apoptosis. The basolateral amygdala was dissected as above and placed into cold PBS to form a single-cell suspension. The final concentration was adjusted to $1 \times 10^{4}$ cells $/ \mathrm{ml}$. Then, $1 \mathrm{ml}$ of the suspension was centrifuged at $1000 \mathrm{~g}$ for 10 minutes at $4^{\circ} \mathrm{C}$ to isolate the supernatant. Finally, $1 \mathrm{ml}$ of cold PBS was added and the supernatant was gently agitated. Centrifugation was repeated three times to obtain the cell pellets. The cell pellets were resuspended in $200 \mu 1$ binding buffer and then incubated with $10 \mu \mathrm{l}$ Annexin V-FITC and $5 \mu \mathrm{l}$ propidium iodide for $15 \mathrm{~min}$ at room temperature. After the addition of $300 \mu \mathrm{l}$ binding buffer, the solution was analyzed by flow cytometry (Becton Dickinson, USA) within one hour.

Brain tissue preparation and TUNEL staining analysis for cell apoptosis. Seven days after exposure to SPS, five rats from each group were transcardially infused with $200-300 \mathrm{ml}$ of pre-cold saline through the ascending aorta, followed by $300 \mathrm{ml}$ of $0.01 \mathrm{M}$ PBS (pH 7.4) containing 4\% pre-cold paraformaldehyde. TUNEL staining was performed as follows: the whole brains were rapidly removed after perfusion fixation with $4 \%$ paraformaldehyde in $0.01 \mathrm{M}$ PBS, dehydrated in alcohol and embedded in paraffin. Next, $5-\mu$ m-thick slices were cut from the paraffin-embedded tissues, washed three times in $0.01 \mathrm{M}$ PBS, then permeabilized in proteinase $\mathrm{K}$ for $10 \mathrm{~min}$. Endogenous peroxidase was deactivated by $0.3 \%$ hydrogen peroxide. After another three washes, the sections were incubated in TdT buffer at $37^{\circ} \mathrm{C}$ for $1 \mathrm{~h}$ and then with antibody at $37^{\circ} \mathrm{C}$ for $1 \mathrm{~h}$. The sections were stained by $\mathrm{DAB}$ with hematoxylin counterstaining and mounted on a light microscope. Five random slides were selected from each group, and from each slide five randomly selected visual fields in the amydala were observed at a magnification of $\mathrm{x} 40$. The number of TUNEL-positive cells was counted, and the TUNEL-positive cell rate was defined as the (number of TUNEL-positive cells/total number of cells) x $100 \%$.

Statistical analysis. Values are presented as the means \pm standard error of the mean (SEM) and were analyzed using SPSS 13.0. Statistical significance was determined by one-way analysis of variance (ANOVA), followed by the Tukey's test when appropriate. A P-value $<0.05$ was considered to indicate a statistically significant difference.

\section{Results}

Bax/Bcl-2 ratio. As seen in Fig. 1, a significant difference in the $\mathrm{Bax} / \mathrm{Bcl}-2$ ratio was observed between the SPS model rats and the control rats (midbrain raphe, $1.39 \pm 0.07$ vs. $0.46 \pm 0.04$, $\mathrm{P}<0.01)$. The same result was observed between the model group and the blockade group: the ratio of $\mathrm{Bax} / \mathrm{Bcl}-2$ was significantly increased in the SPS rats (midbrain raphe, $1.39 \pm 0.07$ vs. $0.79 \pm 0.06, \mathrm{P}<0.01)$. In the rats infused with WAY100635 prior to SPS treatment, the SPS-induced increase in the ratio of $\mathrm{Bax} / \mathrm{Bcl}-2$ in the amygdala was significantly abolished $(\mathrm{P}<0.01)$.

Apoptosis rate. Apoptotic cells were detected by Annexin V/ PI staining in the experimental groups. As shown in Fig. 2, the amygdala cells from the SPS model group underwent considerable apoptosis. ANOVA revealed significant differences among three groups $\left(\mathrm{F}_{2.12}=64.640, \mathrm{P}<0.01\right)$. As shown in Fig. 3, a significant difference in the apoptotic rate was 
A

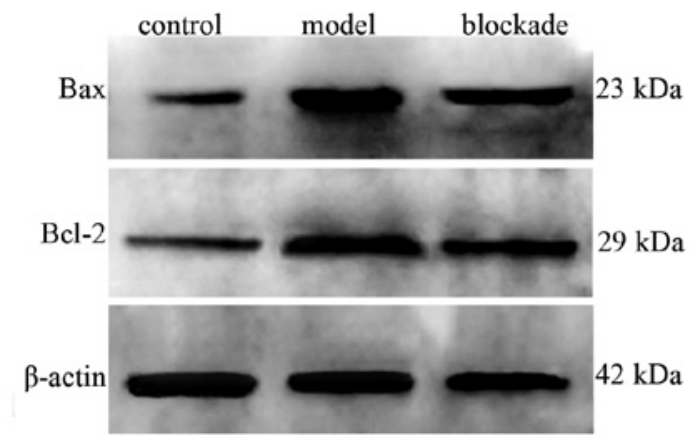

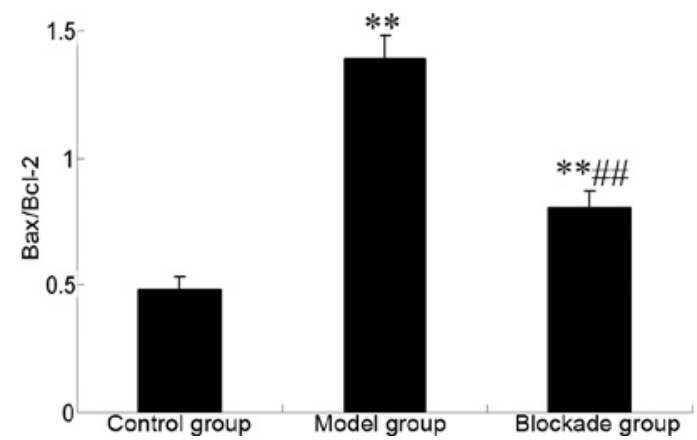

Figure 1. Changes in Bax and Bcl-2 levels in the amygdala of the various groups. (A) Representative results of Western blotting. (B) Changes in the Bax/Bcl-2 ratio ( $n=5$ per group). Statistical analysis was carried out by one-way ANOVA $\left(\mathrm{F}_{2.12}=64.631, \mathrm{P}<0.01\right)$ followed by the Tukey test, ${ }^{* *} \mathrm{P}<0.01$ compared to control group, ${ }^{\# \#} \mathrm{P}<0.01$ compared to the model group.

A

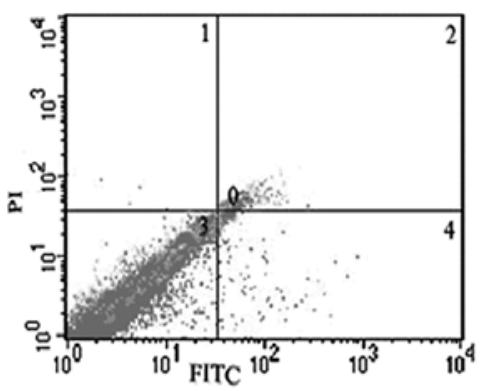

B

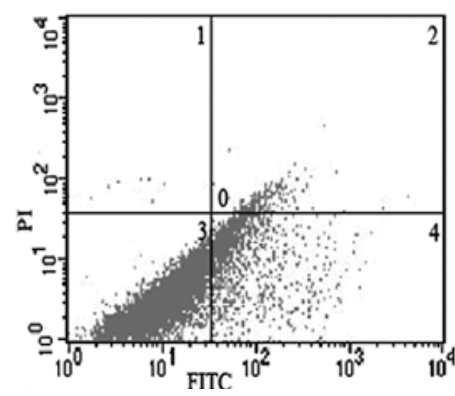

C

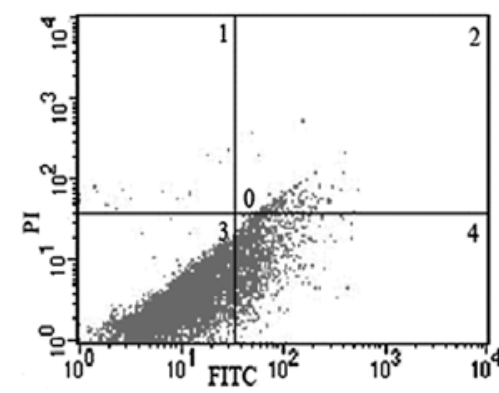

Figure. 2. Apoptosis rate in the amygdala detected by flow cytometry. (A) control group; (B) model group, (C) blockade group. Region 1, necrotic cell population (Annexin $\mathrm{V}^{-} / \mathrm{PI}^{+}$); Region 2, late apoptotic and necrotic cell population (Annexin $\mathrm{V}^{+} / \mathrm{PI}^{+}$); Region 3, viable cell population (Annexin $\mathrm{V}^{-} / \mathrm{PI}^{-}$) and Region 4, early apoptotic cell population (Annexin $\mathrm{V}^{+} / \mathrm{PI}^{-}$).

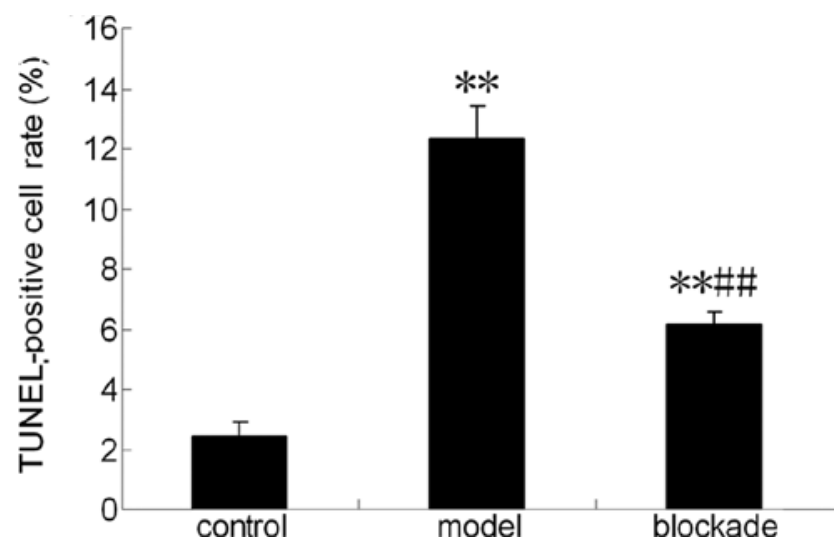

Figure. 3. Analysis of the apoptosis rate by flow cytometry in the amygdala of the various groups ( $\mathrm{n}=5$ for each group). Statistical analysis was carried out by one-way ANOVA $\left(\mathrm{F}_{2.12}=64.640, \mathrm{P}<0.01\right)$ followed by Tukey's test. ${ }^{* *} \mathrm{P}<0.01$ compared to the control group, ${ }^{\# P} \mathrm{P}<0.01$ compared to the model group.

observed between the SPS model rats and the control rats (midbrain raphe, $16.33 \pm 1.62$ vs. $3.01 \pm 0.61, \mathrm{P}<0.01$ ), and between the model group and the blockade group (midbrain raphe, $16.33 \pm 1.62$ vs. $7.77 \pm 1.04, \mathrm{P}<0.01)$. These data indicate that SPS made the amygdala cells prone to apoptosis. In rats infused with WAY100635, the SPS-induced increased in the rate of apoptosis in the amygdala was significantly abolished.

Number and rate of TUNEL-positive cells. The number of TUNEL-positive cells in the control, model and blockade

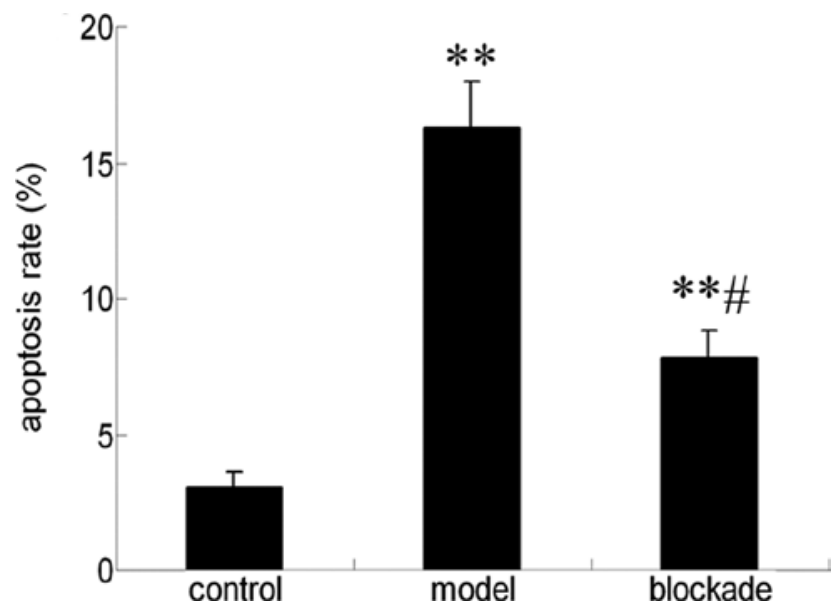

Figure. 4. Analysis of the TUNEL-positive cell rate ( $\mathrm{n}=5$ per group). Statistical analysis was carried out by one-way ANOVA $\left(\mathrm{F}_{2,12}=227.576\right.$, $\mathrm{P}<0.01$ ) followed by Tukey's test. ${ }^{* *} \mathrm{P}<0.01$ compared to the control group, ${ }^{\#} \mathrm{P}<0.05$ compared to the model group.

groups was $12.33 \pm 1.25,62.49 \pm 7.86$ and $38.83 \pm 5.08$, respectively. ANOVA revealed significant differences among the three groups $\left(\mathrm{F}_{2,12}=227.567, \mathrm{P}<0.01\right)$. As shown in Fig. 4, the number of TUNEL-positive cells in the model group was significantly increased compared to the control group $(\mathrm{P}<0.01)$, while the number of TUNEL-positive cells in the blockade group was significantly decreased compared to the model group $(\mathrm{P}<0.01)$. 


\section{Discussion}

PTSD is a stress-related mental disorder caused by a traumatic experience, and is believed to involve the dysregulation of the medial prefrontal cortex and amygdala activity in response to fear. This complex syndrome includes re-experiencing memories (nightmares and flashbacks), symptoms of hyperarousal (e.g., insomnia), numbing symptoms (blunted affect and anhedonia), avoidance symptoms (avoiding trauma-related stimuli), poor concentration and difficulty explicitly recalling aspects of the traumatic event. Since the incidence of wars, violence, natural disasters and major traffic accidents has increased, the incidence of PTSD is on the rise. Therefore, the pathogenesis of PTSD must be precisely elucidated.

SPS induces enhanced inhibition of the HPA axis, a putative neuroendocrinological hallmark of PTSD, presents behavioral alterations resembling those of PTSD and has the most consistent neuroendocrinologic characteristics in PTSD patients (17,20-23). Previous studies have revealed that SPS rats exhibit an exaggerated acoustic startle response (24) and enhanced contextual freezing $(21,25)$. These findings suggest that SPS causes an enhanced sensitivity to stimuli, which resembles trauma-related and -unrelated psychophysiological responses in patients with PTSD. SPS is therefore a good animal model of PTSD based on the time-dependent dysregulation of the HPA axis. In the present study, rats were exposed to SPS to elucidate the pathogenesis of PTSD.

PTSD exhibits four major types of characteristic symptoms: re-experiencing, avoidance, numbing and hyperarousal, suggesting a heightened fear response. Previous studies have demonstrated that the left amygdala volume in PTSD patients is significantly reduced $(5,6,26,27)$. The amygdala is the main output center of response to fearful stimuli (2), and has been documented to be responsible for the enhancement of explicit memories associated with emotional arousal $(3,4)$. PTSD is believed to involve the dysregulation of amygdala activity in response to fear. It has been suggested that the volume of the amygdala in patients with PTSD is significantly reduced $(5,6)$. The basolateral nucleus is the largest subgroup of the amygdala $(28,29)$, and is the key region of fear initiation. Our previous study detected the expression of apoptosis-related genes and observed morphological changes in the asolateral amygdala neurons of PTSD rats (7).

In this study, we investigated the relationship between the SPS-induced activity of the 5-HT1A receptor and apoptosis in the basolateral amygdala. Our results revealed that the Bax/ Bcl-2 ratio, the apoptotic cell rate and the number of TUNELpositive cells in the amygdala increased after the rats were exposed to SPS, suggesting that neuronal apoptosis of the amygdala is induced by SPS. Therefore, apoptosis may play an important role in the decrease in amygdala volume observed in PTSD. Moreover, the results of this study revealed that the apoptosis increase induced by SPS was significantly abolished by WAY100635, an antagonist of the 5-HT1A receptor. Thus, the 5-HT1A recepor may be one of the factors that induces neruon apoptosis in the amygdala.

In conclusion, we demonstrated that apoptosis in the amygdala is associated with the activity of the 5-HT1A receptor. The results suggest that the 5-HT system and apoptosis may play crucial roles in PTSD. The detailed mechanisms of 5-HT and the receptor system in the pathophysiology of stress-related disorders warrants further investigation.

\section{References}

1. American Psychiatric Association: Diagnostic and Statistical Manual of Mental Disorders. 4th edition. American Psychiatric Press, Washington, DC, 1994.

2. Charney DS: Psychobiological mechanisms of resilience and vulnerability: implications for successful adaptation to extreme stress. Am J Psychiatry 161: 195-216, 2004.

3. McGaugh JL: The amygdala modulates the consolidation of memories of emotionally arousing experiences. Annu Rev Neurosci 27: 1-28, 2004.

4. Hamann S: Cognitive and neural mechanisms of emotional memory. Trends Cogn Sci 5: 394-400, 2001.

5. Lindauer RJ, Vlieger EJ, Jalink M, Olff M, Carlier IV, Majoie CB, den Heeten GJ and Gersons BP: Smaller hippocampal volume in Dutch police officers with posttraumatic stress disorder. Biol Psychiatry 56: 356-363, 2004.

6. Karl A, Schaefer M, Malta LS, Dörfel D, Rohleder N and Werner A: A meta-analysis of structural brain abnormalities in PTSD. Neurosci Biobehav Rev 30: 1004-1031, 2006.

7. Ding JL, Han F and Shi YX: Single-prolonged stress induces apoptosis in the amygdala in a rat model of post-traumatic stress disorder. J Psychiatr Res 44: 48-55, 2009.

8. Jarskog LF, Selinger ES, Lieberman JA and Gilmore JH: Apoptotic proteins in the temporal cortex in schizophrenia: high bax/bcl-2 ratio without caspase-3 activation. Am J Psychiatry 161: 109-115, 2004.

9. Cregan SP, Dawson VL and Slack RS: Role of AIF in caspasedependent and caspase independent cell death. Oncogene 23: 2785-2796, 2004.

10. Lucki I: The spectrum of behaviors influenced by serotonin. Biol Psychiatry 44: 151-162, 1998.

11. McAllister-Williams RH, Ferrier IN and Young AH: Mood and neuropsychological function in depression: the role of corticosteroids and serotonin. Psychol Med 28: 573-584, 1998.

12. Millan MJ: The neurobiology and control of anxious states. Prog Neurobiol 70: 83-244, 2003.

13. Gross C, Zhuang X, Stark K, Ramboz S, Oosting R, Kirby L, Santarelli L, Beck S and Hen R: Serotonin1A receptor acts during development to establish normal anxiety-like behaviour in the adult. Nature 416: 396-400, 2002.

14. Tanaka-Gomi N, Yasuda K, Nakamura M, Hasumi-Nakayama Y, Umemura T, Tanaka S and Furusawa K: Postnatal changes in $5 \mathrm{HT}$ and NK1 receptors in rat trigeminal motor nucleus and surroundings. Int J Dev Neurosci 25: 427-432, 2007.

15. Bonne O, Bain E, Neumeister A, Nugent AC, Vythilingam M, Carson RE, Luckenbaugh DA, Eckelman W, Herscovitch P, Drevets WC and Charney DS: No change in serotonin type 1A receptor binding in patients with posttraumatic stress disorder. Am J Psychiatry 162: 383-385, 2005.

16. Haitao W, Fang H and Yuxiu S: Activity of the 5-HT1A receptor is involved in the alteration of glucocorticoid receptor in hippocampus and corticotropinreleasing factor in hypothalamus in SPS rats. Int J Mol Med 24: 227-231, 2009.

17. Liberzon I, Krstov M and Young EA: Stress-restress: effects on ACTH and fast feesback. Psychoneuroendocrinology 22: 443-453, 1997.

18. Shannon HE and Lutz EA: Yohimbine produces antinociception in the formalin test in rats: involvement of serotonin (1A) receptors. Psychopharmacology 149: 93-97, 2000.

19. Paxinos G and Watson C: The Rat Brain in Stereotaxic Coordinates. Academic Press, San Diego, CA, 1998.

20. Liberzon I, López JF, Flagel SB, Vázquez DM and Young EA: Differential regulation of hippocampal glucocorticoid receptors mRNA and fast feedback: relevance to post-traumatic stress disorder. J Neuroendocrinol 11: 11-17, 1999.

21. Takahashi T, Morinobu S, Iwamoto Y and Yamawaki S: Effect of paroxetine on enhanced contextual fear induced by single prolonged stress in rats. Psychopharmacology 189: 165-173, 2006.

22. Kohda K, Harada K, Kato K, Hoshino A, Motohashi J, Yamaji T, Morinobu S, Matsuoka N and Kato N: Glucocorticoid receptor activation is involved in producing abnormal phenotypes of single-prolonged stress rats: a putative post-traumatic stress disorder model. Neuroscience 148: 22-33, 2007. 
23. Yamamoto S, Morinobu S, Fuchikami M, Kurata A, Kozuru T and Yamawaki S: Effects of single prolonged stress and D-cycloserine on contextual fear extinction and hippocampal NMDA receptor expression in a rat model of PTSD. Neuropsychopharmacology 33: 2108-2116, 2008.

24. Khan S and Liberzon I: Topiramate attenuates exaggerated acoustic startle in an animal model of PTSD. Psychopharmacology 172: $225-229,2004$

25. Imanaka A, Morinobu S, Toki S and Yamawaki S: Importance of early environment in the development of posttraumatic stress disorder-like behaviors. Behav Brain Res 173: 129-137, 2006.

26. Bremner JD, Randall P, Vermetten E, Staib L, Bronen RA, Mazure C, Capelli S, McCarthy G, Innis RB and Charney DS Magnetic resonance imaging-based measurement of hippocampa volume in posttraumatic stress disorder related to childhood physical and sexual abuse: a preliminary report. Biol Psychiatry 41: 23-32, 1997.
27. Matsuoka Y, Yamawaki S, Inagaki M, Akechi T and Uchitomi Y: A volumetric study of amygdala in cancer survivors with intrusive recollections. Biol Psychiatry 54: 736-743, 2003

28. Harding AJ, Stimson E, Henderson JM and Halliday GM Clinical correlates of selective pathology in the amygdala of patients with Parkinson's disease. Brain 11: 2431-2445, 2002.

29. Sims KS and Williams RS: The human amygdaloid complex: a cytologic and histochemical atlas using Nissl, myelin, acetylcholinesterase and nicotinamide adenine dinucleotide phosphate diaphorase staining. Neurosci 36: 449-472, 1990. 